\title{
1 \\ The Phenomenal Intentionality Research Program
}

URIAH KRIEGEL

\section{Introduction/Abstract}

Since the late seventies, the main research program for understanding intentionality has been based on the attempt to naturalize intentionality by identifying a natural relation that holds between internal states of the brain and external states of the world when and only when the former represent the latter. Call this the Naturalist-Externalist Research Program, or NERP. Different versions of NERP differ on how they construe the relevant natural relation. Typically, it is construed as involving in its core a type of tracking relation, whereby internal states occur sensitively to the presence of specific external conditions. ${ }^{1}$

Some philosophers, however, have remained skeptical of this entire approach. In particular, some have argued that phenomenal consciousness has an essential role to play in the theory of intentionality, a role it is not accorded in NERP. Thus a number of authors have recently brought to the fore the notion of phenomenal intentionality, as well as a cluster of nearby notions. There is a vague sense that their work is interrelated, complementary, and mutually reinforcing, in a way that suggests a germinal research program-what I call the Phenomenal Intentionality Research Program, or PIRP.

My principal goals in this chapter are the following. First, I will explicitly articulate, and elaborate upon, what I take to be the fundamental claims at the heart of this nascent research program. Secondly, I will review some of the arguments in the recent philosophical literature that support key theses of PIRP, in the process illustrating some apparent advantages of the framework in comparison to NERP. Thirdly, I will point out some important theoretical options within the generic PIRP framework, specifying issues about which proponents of the general framework might disagree. 


\section{An Overview of PIRP}

Phenomenal intentionality is the intentionality a mental state exhibits purely in virtue of its phenomenal character. As far as I know, the term makes its first appearance in two papers circulating in the second half of the nineties, Brian Loar's (2003) "Phenomenal Intentionality as the Basis of Mental Content" and Terry Horgan and John Tienson's (2002) “The Phenomenology of Intentionality and the Intentionality of Phenomenology." Loar's paper started circulating in the late nineties, however, and in any case the idea of phenomenal intentionality is present in Loar's work much earlier. His 1987 paper "Subjective Intentionality" may be regarded as the first explicit published discussion of phenomenal intentionality in analytic Anglo-American philosophy. Arguably, however, the lively debates on intentionality among Brentano and his students (see Brentano 1874, Twardowski 1895, Husserl 1901, and Meinong 1904) in fact concerned phenomenal intentionality, which was probably the only intentionality they recognized. ${ }^{2}$

\subsection{Toward a New Research Program}

The term "research program" can be used to intimate two different things. In one sense, the term is used to refer to a degraded kind of theory-a cluster of ideas whose purpose is to become a comprehensive theory of some phenomenon but which has not yet reached the maturity and cohesion required. In another sense, the term is used to denote a perfectly clear general framework for the study of some phenomenon, a framework within which several distinct theories could be pursued that share a fundamental commonality (a "paradigm" perhaps). My claim here is that work on phenomenal intentionality is on the cusp of qualifying as a research program in the second.

Compare NERP, where a number of distinct theories can be discerned-informational semantics, functional role semantics, teleosemantics - that nonetheless share the general idea that some kind of naturalistically kosher relation between brain events and world events must underlie intentionality. Put impressionistically, the basic idea shared by all theories within NERP is that intentionality is injected into the world with the appearance in nature of a certain kind of tracking relation. It is when the relevant tracking relation occurs between distinct states (including brain states and environmental states) in the world that intentionality makes its first appearance on the scene. Once intentionality has thus been injected into the world, it can start being "passed around" so it is somewhat "freed from" the relevant tracking relation. Linguistic expressions, paintings, and traffic signs, for example, may represent even in the absence of tracking, because they somehow derive their intentionality from things that do track. But the source of all intentionality is the relevant kind of tracking relation. Something like this is the paradigm that guides work on intentionality within NERP. 
The basic, guiding idea of PIRP could be thought of on the same model (Kriegel 2011). The cornerstone would be the idea that intentionality is injected into the world with the appearance of a certain kind of phenomenal character. It is when the relevant phenomenal character shows up that intentionality makes its first appearance on the scene. Here too, once this phenomenal character appears, and brings in its train "original intentionality," intentionality can be "passed around" to things lacking this (or any) phenomenal character. But the source of all intentionality is the relevant phenomenal character.

Within NERP, different comprehensive theories of intentionality may differ along two central dimensions. First, they may differ on what they identify as the relevant tracking relation that brings intentionality into the world. Is it a causal relation, an informational relation, a counterfactual-dependence relation, a teleological relation? Much of the debate on intentionality during the eighties concerned this question. Secondly, they may differ on how they choose to account for derived intentionality, in language and other forms of tracking-free intentionality. ${ }^{3}$ The leading account here is probably Grice's (1957, 1969) intention-based theory (see also Schiffer 1982), which is most naturally applied to language, but may also be extended to pictorial representation (Abell 2005, Blumson 2006) and perhaps other forms of derived intentionality. One may say, then, that comprehensive theories of intentionality within NERP are composed of two chapters, namely, (i) an account of the relevant tracking relation and (ii) an account of the derivation relation (in the relevant sense). ${ }^{4}$

More generally, the two chapters concern source intentionality (if you will) and non-source intentionality. This general structure can be reproduced for PIRP. This would be to think of a comprehensive theory of intentionality as involving the following two chapters: (i) an account of the kind of phenomenal character that constitutes source intentionality and (ii) an account of the derivation relation that underlies non-source intentionality. Accordingly, different theories of intentionality within PIRP would differ in the kind of phenomenal character they identify as the source of all intentionality and/or in how they choose to account for phenomenality-free intentionality (in language, pictures, unconscious mentation, etc.). ${ }^{5}$

In the remainder of this section, I offer a first pass at understanding PIRPwhat it attempts to do ( $\$ 1.2)$ and how it attempts to do it (\$1.3). Later, I will review some of the main ideas surrounding the notion of phenomenal intentionality ( $\$ 2)$, then outline the structure of a general theory of intentionality within PIRP (§3).

\subsection{Location Projects and the Theory of Intentionality}

Jackson (1998) usefully describes the core of what he calls "serious metaphysics" as the project of addressing the "location problem": the problem of finding a place 
for some phenomenon (typically familiar from the manifest image) in description of the world cast entirely in some privileged vocabulary. In fact, however, there appear to be two kinds of location problem one might distinguish. I will call these naturalistic location and foundational location (respectively). ${ }^{6}$

Roughly and generically, naturalistic location of a puzzling phenomenon (e.g., intentionality) is a matter of identifying it with some phenomenon also describable in such a way that the phenomenon, as thus alternatively described, counts as "non-mysterious" and "kosher" within a metaphysical perspective that gives pride of place to natural science. In the case of naturalizing intentionality, the project is to locate intentionality in a world fully described by the natural sciences. To do so is to "naturalistically locate" intentionality.

Naturalistic location thus involves taking the vocabulary of the natural sciences to be the privileged vocabulary in serious metaphysics. Foundational location, on the other hand, involves taking some other vocabulary, considered in some sense foundational, to be privileged. In the case of intentionality, for example, foundational location is, roughly, a matter of (i) identifying the fundamental source(s) of intentionality in the world (the way it gets "injected" into the world), and (ii) identifying the principal way(s) derivative kinds of intentionality arise from it.

Within NERP, the two kinds of location project-foundational and naturalizing-are effectively pursued in tandem. Proposed "sources" are naturalistically respectable phenomena (causal, covariational, informational, or teleological relations); and their spread to non-source intentionality is construed as naturalistically respectable as well. Part of the philosophical motivation for proposing such sources is the desire to foundationally locate intentionality in a manner that also constitutes naturalistic location of these phenomena.

Within PIRP, things proceed differently. Pride of place is given to the idea that phenomenal consciousness is implicated in the source of intentionalityit somehow founds, or grounds, all intentionality. ${ }^{7}$ Naturalization, if it is to come at all, needs to be a naturalized version of PIRP (“NPIRP," if you will).

\subsection{Fundamental Tenets of PIRP}

As noted earlier, work on phenomenal intentionality already qualifies as a research program in the looser sense, since many interrelated theses recur in discussions of the notion. I now propose, in rough and generic terms, an explicit articulation of the common basic ideas that are implicit in this work on phenomenal intentionality. The six theses below will be put somewhat vaguely, in order to be suitably generic. ${ }^{8}$ It would be too much to expect that all philosophers who qualify as pursuing PIRP subscribe to all six theses. But my suggestion is more modest: that (a) most would subscribe to all six theses and (b) all 
would subscribe to most theses. ${ }^{9}$ I first present the six theses, then offer some initial clarification of each.

Phenomenal Grounding. There is a kind of intentionality-phenomenal intentionality-that is grounded in phenomenal character.

Inseparatism. The phenomenal and the intentional do not form two separate mental realms, but are instead inseparably intertwined.

Distinctiveness. Phenomenal intentionality is special and distinctive, in that it has certain important properties that non-phenomenal forms of intentionality do not.

Narrowness. Phenomenal intentionality is narrow, that is, it is not constitutively dependent upon anything outside the experiencing subject.

Subjectivity. Phenomenal intentionality is inherently subjective: it is built into the phenomenal character of a phenomenally intentional state that it (re)presents what it does to someone.

Basicness. Phenomenal intentionality is a basic kind of intentionality and functions as a source of all intentionality.

Some initial clarifications are in order. Regarding Phenomenal Grounding, what the pertinent kind of grounding comes to, metaphysically, is a matter about which different PIRPers could go different ways. One clarification is essential though: somewhat atypically, as I use the term "grounding," the grounding relation need not be anti-symmetric. On the contrary, it could well be that the phenomenal property and the intentional property it grounds are strictly identical. (More on that in 1.4.)

As for Inseparatism, a traditional picture divided the mind into two separate realms: sensory states, which are essentially phenomenal but non-intentional, and cognitive states, which are essentially intentional but non-phenomenal (Horgan and Tienson 2002). This is what Inseparatism rejects, holding instead (i) that paradigmatic sensory states in fact exhibit intentionality, which is moreover grounded by their phenomenality, and (ii) that paradigmatic cognitive states in fact boast a phenomenality, which moreover grounds their intentionality.

Next consider Distinctiveness. This is the idea that there is something special about phenomenal intentionality that sets it apart from other kinds of intentionality. Phenomenal intentionality has certain significant peculiarities. Part of the reason the notion of phenomenal intentionality becomes the focus of dedicated research is precisely this distinctiveness.

Concerning Narrowness, now, an intentional property is narrow just in case it supervenes on the subject's non-relational properties, that is, is "locally supervenient." Thus to say that phenomenal-intentional properties are narrow is to say that they are locally supervenient. 
As for Subjectivity, I note that recent philosophical work on phenomenal consciousness has increasingly emphasized the fact that phenomenal character has to do not just what it is like but with what it is like for the subject. This feature is inherited by phenomenal intentionality: a phenomenally intentional state presents what it does to the subject. (More on this in 2.3.)

Finally, Basicness is essentially the thesis that all intentionality derives from phenomenal intentionality. It appears to follow from this that in the absence of phenomenal intentionality there would be no intentionality at all. Clearly, this is a linchpin thesis for the foundational location project.

\subsection{Some Theoretical Options within PIRP}

There are a number of important issues about which proponents of the generic PIRP framework could take different positions. Here I will briefly describe some of these issues and some principal theoretical options concerning them. ${ }^{10}$

First is the relation between phenomenal properties and fundamental intentional properties. One view is that the "relation" is outright identity: the intentional property just is the phenomenal property. An alternative view is that phenomenal properties are distinct from the relevant intentional properties, that the intentional properties supervene with metaphysical necessity upon the phenomenal properties, and/or that the intentional properties are realized by the phenomenal properties. A third option is that there is an anti-symmetric relation of metaphysical dependence that the intentional properties bear to the phenomenal properties and that goes beyond mere supervenience-a sort of "in virtue of" relation. There may be other options as well.

Second is the extent of phenomenal intentionality. One view is that phenomenal intentionality is confined to perceptual experience, or to this plus somatic and emotional experience. Another view is that it is much more pervasive, including for instance the phenomenology of agency, the phenomenology of thought (so-called cognitive phenomenology), and so on. ${ }^{11}$ Embracing the leaner view presumably would greatly complicate the task of making a case for Basicness; the wider the extent of phenomenal intentionality, the more tenable Basicness is. However, there is nothing incoherent about pursuing PIRP while rejecting an expansive account of phenomenology. One could perfectly well hold that all phenomenology is sensory and nonetheless subscribe to all six theses listed earlier. This is important, because some commentators discuss the notion of phenomenal intentionality as though it is definitionally tied to the possibility of cognitive phenomenology (e.g., Lycan 2008).

Third is the question of whether (some or all) phenomenally intentional states exhibit any kind of non-foundational, merely derived intentionality along with their underived source intentionality. One view is that some or all do, one that none do. 
Fourth is the question of whether phenomenal intentionality is in fact naturalistically, or even physicalistically, locatable. One view is that it is, even though the relevant kind of naturalization evidently would need to look rather different from NERP. The opposite view is that phenomenal-intentional properties are primitive and irreducible (or at least not reducible to physical properties). ${ }^{12}$

\section{Arguments for Central PIRP Theses}

In this section, I survey various arguments from the recent philosophical literature pertaining to the existence of phenomenal intentionality, its scope and extent in human mentality, its distinctive features, and its basic role as the source of all intentionality.

\subsection{The Existence of Phenomenal Intentionality}

Why think that there is such a thing as phenomenally grounded intentionality? One consideration unlikely to win converts but central in motivating sympathizers is the idea that phenomenal intentionality is simply introspectively manifest: attending to one's stream of consciousness in the right way brings out that some conscious episodes are intentional, and intentional because phenomenal. Certainly introspection suggests that some mental states have both intentionality and phenomenality. Whether introspection reveals that sometimes the former is grounded in the latter is a harder question. Admittedly, it is implausible that introspection presents any grounding relation as a grounding relation. But it is much more plausible that introspection presents what is in fact a grounding relation under a simpler guise, but in such a way that a sufficiently sophisticated theoretician could justifiably conceptualize what is presented as grounding. ${ }^{13}$

An argument with a more neutral starting point is due to Charles Siewert (1998). He notes that, purely in virtue of their phenomenal character (and without need of interpretation), conscious experiences are often assessable for accuracy. Suppose you undergo an experience with a squarish phenomenal character. If nothing around you is square, your experience is assessable as inaccurate. If the right object or surface is square, your experience may be assessable as accurate. Thus phenomenal character can bring in its train accuracy conditions. Since having accuracy conditions is an intentional property, it appears that at least some phenomenal character can guarantee intentional properties.

Finally, the existence of phenomenal intentionality may be supported with thought experiments. For instance, we can conceive of a disembodied soul in 
an otherwise empty world who is phenomenally indistinguishable from us (Kriegel Ms). Intuitively, portions of the soul's inner life are also intentionally indistinguishable (in the sense of instantiating the same intentional properties) from corresponding portions of our own inner life-we and the soul will have some intentional states in common. The fact that some phenomenal duplication secures intentional duplication suggests (perhaps entails) that some phenomenal properties are sufficient for intentional properties. Another thought experiment is the more familiar brain-in-vat one (Horgan et al. 2004). Intuitively, an envatted brain that is physically identical throughout its existence to your brain, with identical sensory inputs all the while, would have a conscious mental life that intentionally matches yours exactly. And intuitively, the basis for this intentional match would be that this envatted brain would have a mental life some of which is phenomenally exactly like yours.

\subsection{The Scope of Phenomenal Intentionality}

Once one knows that there is phenomenal intentionality in the world, one wants to know just how much of it there is. Much of the work carried out by PIRPers concerns this question.

The question may be profitably divided into two sub-questions, concerning (respectively) sensory and non-sensory phenomenal intentionality. The challenge presented by each question has been quite different. In the sensory domain, it is widely acknowledged that there is sensory phenomenology; the challenge has been to show that there is a sensory intentionality it grounds. In the non-sensory domain, it is widely acknowledged that there is non-sensory intentionality; the challenge has been to show that there is a non-sensory phenomenology that grounds it. In this section, I review some work on non-sensory phenomenal intentionality. ${ }^{14}$ This work has tended to fall in turn into two categories, concerned with phenomenal intentionality within and without the sphere of perceptual experience.

Within the perceptual sphere, there are elements in perceptual experience that are intentionally rich but are claimed to nonetheless involve phenomenal intentionality. Perhaps the most systematic contribution to the study of perceptual phenomenal intentionality is due to Susanna Siegel (2005, 2006a), who argues that high-level properties are represented in perception. These include causation, meaning, and kind properties. The idea is that we not only understand, but can also perceive, that one billiard ball causes the motion of another; that some words on a page mean that the basketball game has been canceled; that something colorful and shapely is a parrot (see also Siewert 1998).

A particularly intriguing debate in this area concerns the point at which perceptual experiences start presenting us with an objective world, a world whose character is independent of the subject's perceptual activity. Siegel 
(2006b) herself argues that this occurs when part of the content of a perceptual experience is that its object will not move if the subject changes her spatial perspective on it. Farid Masrour (2008) argues that this occurs rather when the experience acquires a certain phenomenal feature he calls "dynamic unity structure." ${ }^{15}$ Other views are also possible.

A related and quite central debate concerns the representation of perspectival properties. Suppose you look at a tilted coin. Does your perceptual experience present the coin as (having the non-perspectival property of being) circular or as (having the perspectival property of being) elliptical? Kelly (2004) argues that only the (non-perspectival) circularity is presented in experience, whereas Noë (2004) claims that both the (non-perspectival) circularity and (perspectival) ellipticality are presented.

For a variety of reasons, friends of phenomenal intentionality have often been keen to argue for the existence of non-perceptual experience with a purely intellectual or cognitive phenomenology that constitutes its intentionality. Perhaps the strongest thesis in this vein is Pitt's (2004) claim that thoughts have a phenomenology which is both proprietary and individuative, that is, a phenomenology that both is different from all other types of phenomenology and varies whenever the content varies. ${ }^{16}$

The literature contains two main types of argument for claims of this sort (though there are at least three more minor types of argument I will not survey here). One is an argument from phenomenal contrast: two conscious episodes are contrasted, where (i) there is clearly an overall difference in what it is like to undergo these episodes and (ii) the best account of that difference is in terms of a difference in a purely cognitive phenomenal character. A much discussed argument of this form is due to Strawson (1994), though it is present in essence already in Moore (1953). Strawson argues for the existence of "understanding experience" by contrasting the overall phenomenologies of a French speaker and a non-French speaker listening to the news in French. Strawson claims that there is a difference in what it is like for them to listen to the news, and that the difference is best accounted for in terms of an element of understanding experience present only in the French speaker's phenomenology. ${ }^{17}$

The second kind of argument appeals to an asymmetric access one has to one's conscious cognitive states and their contents (Goldman 1993, Pitt 2004). Schematically, the argument proceeds as follows: one has a special, immediate access to some of one's cognitive states (and their contents); only to phenomenal states (and contents) can one have this kind of special access; therefore, (some of) one's cognitive states (and their contents) are phenomenal.

This is a very partial survey of research in this area. The telos of this research appears to be to establish that sensory states' phenomenology is inherently intentional and that non-sensory states' intentionality is phenomenally grounded. If something like this is established, then the separatist picture 
of the mind collapses, and a more unified picture emerges that conforms to Inseparatism (see §1.3). One way to develop the inseparatist picture is to construe the concept of mind as a prototype concept, such that a state or event qualifies as mental to the extent that it is appropriately related to prototypical mental states, but where all (and perhaps only) prototypical mental states are phenomenally intentional states (Horgan and Kriegel 2008).

\subsection{The Distinctiveness of Phenomenal Intentionality}

Another focal point of much work on phenomenal intentionality is the thought that there is something special about phenomenal intentionality-that phenomenal intentionality exhibits significant distinctive features absent in other types of intentionality. This is important, because if phenomenal intentionality is indeed distinctive, it may resist theoretical treatment perfectly suitable for other types of intentionality. For example, one might hold that while teleosemantics is the true theory of non-phenomenal intentionality, some other theory would be needed to accommodate the distinctive features of phenomenal intentionality.

One recurrent distinctiveness claim is that only phenomenal intentionality has determinate content in and of itself (Searle 1991, 1992, Loar 1995, Horgan and Tienson 2002, Strawson 2008, Horgan and Graham forthcoming). We may state this thesis as follows:

Determinate Content. Necessarily, for any intentional state $\mathrm{M}$ with content $C$, if $C$ is non-derivatively determinate, then $M$ is phenomenally intentional.

On this view, non-phenomenally intentional states can have determinate content, but not in and of themselves. Instead, they must derive their determinate content from phenomenally intentional states they are appropriately related to. By "determinate content," I simply mean content which is as fine-grained as one's intentional contents appear pre-theoretically to be. For example, pre-theoretically it seems that one's thoughts are fine-grained enough to be about rabbits rather than undetached rabbit parts, about Phosphorus rather than Hesperus, about triangles rather than closed trilateral figures, and so on. If a kind of intentional state is not this fine-grained, I say that its content is indeterminate. And if it is this fine-grained, but not intrinsically so, I say that its content is only derivatively determinate. Determinate Content claims that only phenomenally intentional states have non-derivatively determinate content. $^{18}$

One key argument for this thesis, in very rough outline, is that nothing other than phenomenal character can secure content determinacy. 
In particular, tracking relations cannot account for this determinacy-not even when teleologically augmented. Whenever an internal state bears tracking relations to rabbits or Phosphorus, it also bears them to undetached rabbit parts or Hesperus. And as Fodor $(1984,1990)$ argued long ago, whenever tracking a property $\mathrm{F}$ is adaptive for an organism, it is also and equally adaptive for it to track any property coextensive with F. Evolutionary benefit cannot discriminate between coextensive properties (let alone necessarily coextensive ones). Of course, for all I just said, there may be some other non-phenomenal feature that can secure content determinacy, but proponents of Determinate Content have attempted to consider all the initially plausible candidates and argue against them (see especially Horgan and Graham forthcoming).

Another claim with the same general structure is that only phenomenal intentionality is intrinsically subjective (McGinn 1988, Kriegel 2003b, Georgalis 2006). Put in McGinn's (1988) terms, the basic idea is that conscious content is Janus-faced, in that in addition to its outward-looking face of presenting some object or state of affairs in the world, it also possesses an inward-looking face involving an elusive presence to the subject. This can perhaps be interpreted more rigorously as the thesis that while unconscious intentional states instantiate in and of themselves only the two-place relation $x$ represents $y$, conscious ones instantiate the three-place relation $x$ represents $y$ to $z$. Let us say that an intentional state $\mathrm{M}$ is non-derivatively subjective just in case it instantiates the three-place representation relation intrinsically, that is, in and of itself. ${ }^{19}$ Then we may put the thesis as follows:

Intrinsic Subjectivity. Necessarily, for any intentional state $\mathrm{M}$, if $\mathrm{M}$ is non-derivatively subjective, then $\mathrm{M}$ is phenomenally intentional.

The thesis allows unconscious intentional states to instantiate the three-place representation relation, but not intrinsically. Rings on a tree trunk can represent the tree's age to a botanist, and an unconscious state in the dorsal stream of the visual system can represent a circle to a neuroscientist. But in these cases, the representation-to is not inherent in the representation-of. Rather, the representation of a worldly feature represents what it does to someone simply because someone harbors a separate representation of it; it is only thanks to this other (second-order) representation that the original (first-order) representation represents to someone. Phenomenally intentional states, by contrast, are non-derivatively subjective in that they represent what they do to someone without requiring that "someone" to harbor a numerically distinct representation of them.

It is not easy to discern in the existing literature a clear argument for Intrinsic Subjectivity. This is probably because the pull of the thesis is mostly phenomenological. It has sometimes been claimed, on broadly phenomenological 
grounds, that all conscious states necessarily involve a kind of for-me-ness, or subjective significance, whereby their subject is aware of them in an immediate and somewhat elusive manner (Levine 2001, Kriegel 2005, 2009, Horgan et al. 2006). It is natural to think that when an intentional state is conscious, its for-me-ness will manifest itself as the kind of non-derivative subjectivity under discussion.

Here too it is clear that the intrinsic subjectivity of phenomenally intentional states creates a prima facie problem for NERP, as the latter is geared to account mostly for representation-of, not representation-to. Perhaps one exception is Millikan's (1989) consumer semantics, which may be naturally thought of as capable of accounting for representation-to. In consumer semantics, the content of a representation $\mathrm{R}$ is determined not by the way the system that produces $\mathrm{R}$ tracks conditions in the world, but by the way the downstream systems that consume $\mathrm{R}$ track them. In a way, we may say that it is what $\mathrm{R}$ represents to the consumer systems that determines R's content. Thus consumer semantics offers a NERP-y gloss on representation-to. However, it is unclear that this type of representation-to is the one referred to by proponents of Intrinsic Subjectivity. For starters, the latter is always and necessarily a personal-level phenomenon, whereas the former can be a sub-personal phenomenon. Likewise, since the latter is a phenomenal element and the former is a matter of accessibility or consumability, it would appear that the latter is an occurrent property whereas the former is a dispositional one. Fuller discussion of these issues cannot be attempted in this review, but clearly there are some principled obstacles in the way of a consumer-semantic account of representation-to. ${ }^{20}$

A third distinctiveness claim that shows up often in the relevant literature is that phenomenal intentionality always involves narrow content, in the sense of being shared by intrinsic duplicates, whereas non-phenomenal intentionality often involves wide content (Loar 2003, Horgan and Tienson 2002, Horgan et al. 2004, Georgalis 2006, Kriegel 2007, 2011). ${ }^{21}$ If a kind of content internalism were generally true of phenomenal intentionality, while content externalism were commonly true of non-phenomenal intentionality, that would constitute another distinction of phenomenal intentionality. Any distinctiveness thesis based on narrowness, however, would have to stress a quantificational difference only: phenomenal intentionality is always narrow, whereas non-phenomenal intentionality is only sometimes narrow. For it is clear that non-phenomenal intentionality can be and often is narrow as well. For some non-phenomenal representations represent non-Twin-Earthable properties. For example, an unconscious representation of a chair is arguably shared by intrinsic duplicates, since arguably there are no Twin-Earth scenarios in which something looks superficially like a chair but lacks some chairly underlying nature.

Arguments for internalism about phenomenal intentionality vary depending on the strength and nature of the internalism. But the basic argument for 
the narrowness of phenomenal intentionality is fairly straightforward (Horgan et al. 2004): phenomenal intentionality supervenes on phenomenal character; phenomenal character is locally supervenient; therefore, phenomenal intentionality is locally supervenient. The first premise is more or less definitional, the second is supported by brain-in-vat thought experiments (involving phenomenal duplicates that lack the relevant relations to the environment), and the inference is buttressed by the transitivity of supervenience.

Content determinacy, intrinsic subjectivity, and narrowness are recurring central claims among philosophers working on phenomenal intentionality. There are other, more idiosyncratic claims that can and have been made, but which will not be discussed here.

\subsection{The Basicness of Phenomenal Intentionality}

Perhaps the most important kind of claim made on behalf of phenomenal intentionality is that it is in some way basic among forms of intentionality (e.g., as in $\S 1.2)$. In this section, I review first the main theses alleging basicness, then the kinds of argument that have been offered in their favor.

The strongest possible basicness thesis is that, in reality, there is no intentionality but phenomenal intentionality-all intentionality is phenomenal (Strawson 2008, Georgalis 2006). ${ }^{22}$ On this view, it is simply false that there is any non-phenomenalintentionality. Theremaywell bea variety of information-bearing states, but for one reason or another those do not qualify as intentional states. The only states that qualify as intentional are phenomenal ones.

A more lenient view allows for some non-phenomenal intentionality but claims that any such must derive from phenomenal intentionality (McGinn 1988, Kriegel 2003b, 2007, 2011). The distinction between derived and underived intentionality was brought into modern discussions of intentionality by Grice (1957), who suggested that the intentionality of language derived from the intentionality of thought: the linguistic symbol $c^{\wedge} a^{\wedge} t$ represents cats only in virtue of bearing a certain relation to cat thoughts, whereas cat thoughts have cat-representing content in and of themselves. More generally, it has often been suggested that all non-mental intentionality derives from mental intentionality (see Cummins 1979, Searle 1983, Dretske 1988). But proponents of phenomenal intentionality, while embracing the distinction between derived and underived intentionality, have sometimes sought to draw it more restrictively, claiming that the intentionality of non-phenomenal mental states derives from that of phenomenal ones. Thus non-phenomenal mental states and non-mental items may be intentional, but they must derive their intentionality from phenomenally intentional states.

A slightly weaker thesis that might easily be confused with this holds that phenomenal intentionality is the only underived intentionality, and all non-phenomenal intentionality is derived, but does not claim that 
non-phenomenal intentional states (and items) derive their intentionality from phenomenal-intentional states (Bourget 2010). Instead, it allows non-phenomenal states to derive their intentionality from each other, in contrast to phenomenal-intentional states, each of which has its intentionality independently of other intentional states.

A significantly weaker claim allows non-phenomenal states to boast underived intentionality but requires that such states be potentially phenomenal-intentional (Searle 1991, 1992). In other words, only states that could potentially have phenomenal intentionality have underived intentionality. Presumably, these states have their intentionality precisely because they could potentially become phenomenal-intentional. Thus, a tacit and unconscious belief that $13.46>8.27$ is endowed with underived intentionality, but only because it could be conscious. Indeed, its intentional content is partly determined by the phenomenal character it would have if it were conscious.

A thesis weaker yet would require non-phenomenal states to bear some relation to phenomenal states in order to qualify as non-derivatively intentional, but not necessarily the relation of "potentially becoming" (or "potentially being"). Instead, it would allow various inferential and/or causal relations to experiential states to suffice for derived intentionality (Horgan and Tienson 2002, Horgan and Graham forthcoming, Loar 2003). As Davies (1995) notes, some sub-personal states, such as Marr's (1982) 2.5D sketches, are naturally construed as non-derivatively intentional but are not even potentially conscious by any intuitive construal of "potentially." However, even such states are cognitively integrated into a system of inferentially interrelated intentional states some of which are phenomenally conscious. It may therefore be suggested that being thus integrated is a necessary condition on a mental state's being non-derivatively intentional. On this view, a mental state qualifies as intentional only if it is related to phenomenally conscious states by the relation of being integrated into a single inferential web. ${ }^{23}$

In sum, there are four main grades of basicness claims discernible in the existing literature:

(B1) All intentionality is phenomenal intentionality. (Strawson, Georgalis)

(B2) All intentionality derives from phenomenal intentionality. (McGinn, Kriegel)

(B3) All intentionality derives from potentially phenomenal intentionality. (Searle)

(B4) All intentionality derives from intentionality appropriately related to phenomenal intentionality. (Horgan et al., Loar)

Although the theses are different, the arguments adduced in their favor are often neutral between them and can be wielded in defense of several or any. 
I end this section with a review of the main arguments to be found in the literature. In the present context, I am not endorsing any of them; my purpose is merely expository.

Most of these arguments follow a similar schema (Kriegel 2003b). First, an asymmetry is established between phenomenal and non-phenomenal intentionality, along the lines of one of the distinctiveness claims surveyed in $§ 2.3$. Then, it is argued that the distinctive feature of phenomenal intentionality is mandatory in the basic kind of intentionality (the underived kind, the occurrently underived kind, or the not-merely-relationally underived kind). It is then concluded that only phenomenal intentionality is basic. Thus a schema for an argument for the primacy of phenomenal intentionality emerges: 1) Only phenomenal intentionality has feature F; 2) Only intentionality with feature F is basic; therefore, 3) Only phenomenal intentionality is basic.

An argument from Determinate Content fitting this schema would proceed as follows: 1) Only phenomenal intentionality has non-derivatively determinate content; 2) Only intentionality with non-derivatively determinate content is basic; therefore, 3) Only phenomenal intentionality is basic. This is probably the most common type of argument for the basicness of phenomenal intentionality one finds in the relevant literature (see Loar 1987, 1995, Searle 1992, Horgan and Tienson 2002, Strawson 2008, Georgalis 2006, and Horgan and Graham forthcoming). The central claim of Loar's argument, for instance, is that non-phenomenal states, left to their own devices, so to speak, would be referentially inscrutable-there would be nothing to make them about rabbits, say, rather than undetached rabbit parts (see especially Loar 1995). Only phenomenally intentional states are referentially "scrutable" (if you will) in and of themselves: there is something about their phenomenal character that makes them about rabbits rather than undetached rabbit parts. Yet we must suppose that intentional content is always determinate, hence "scrutable." So non-phenomenally intentional states must derive their determinate content (or derive the determinacy of their content) from phenomenally intentional states. ${ }^{24}$ Searle (1992) also appeals to content (in)determinacy in his argumentation, though of a different type. For Searle, the threat is that intentional content turn out to be indeterminate between different ways one and the same worldly target could be presented (e.g., Hesperus and Phosphorus). But the distinctive feature of phenomenal intentionality he appeals to is essentially the same "inherent determinacy" invoked by Loar. ${ }^{25}$

Another type of argument fitting the same schema starts from the premise of Intrinsic Subjectivity (McGinn 1988, Kriegel 2003b, Georgalis 2006, Frey this volume). As McGinn puts it, phenomenal intentionality is Janus-faced: it has an outward-looking face, which has to do with what it presents, but also an inward-looking face, to do with who it presents it to. ${ }^{26}$ The thought, 
presumably, is that such Janus-faced content, and the intrinsic subjectivity it bestows, are required for basic intentionality. If so, the fact that only phenomenal intentionality features it entails that only phenomenal intentionality is basic. Fitting this into the above schema, we obtain the following: 1) Only phenomenal intentionality is intrinsically subjective; 2) Only intrinsically subjective intentionality is basic; therefore, 3) Only phenomenal intentionality is basic.

Interestingly, it is harder to identify in the literature a similar argument from Narrowness. Perhaps this is because the starting point of such an argument would have to be the premise that mental states with basic intentionality must have narrow content, and in the present philosophical climate, this would seem grossly question-begging. This is an interesting predicament, given that it is precisely the internalist promise of phenomenal intentionality that attracts its proponents in the first place. One argument that can be interpreted as revolving around narrow content appeals to the phenomenon of intentional inexistence: the fact that every intentional state can occur in the absence of that which it is about. On one version of the argument (Kriegel 2007), it is claimed that only adverbially intentional states exhibit intentional inexistence in and of themselves, and then that only phenomenally intentional states are adverbial. An adverbial intentional state, being entirely non-relational, would clearly have narrow content, so this can be seen as an argument for a basicness thesis from a narrowness one.

Bourget (2010) offers an importantly different kind of argument. He claims that holism about intentionality, according to which intentional contents are assigned in the first instance to networks of interrelated states rather than individual states, is true of non-phenomenally intentional states but not of phenomenally intentional ones. In consequence, non-phenomenal states partially derive their intentional properties from other non-phenomenal states. By contrast, since holism is false of phenomenally intentional states, the latter's intentionality is underived: each phenomenally intentional state has its content irrespective of any relations to other states. Here the designated distinctive feature of phenomenal intentionality appears to be a sort of intentional atomism, and the resulting argument takes the following form: 1) Only phenomenal intentionality is atomistic; 2) Only atomistic intentionality is basic; therefore, 3) Only phenomenal intentionality is basic.

As stressed earlier, I am not concerned here with the persuasiveness of any of these arguments, nor for that matter with the plausibility of their conclusions. ${ }^{27}$ The purpose of this section has been to review the kind of work that has already been done on the notion of phenomenal intentionality. This work has focused on four main questions: concerning the existence, scope, distinctiveness, and basicness of phenomenal intentionality. 


\section{The Structure of a General Theory of Intentionality}

In this section I consider how a general theory of intentionality would look within PIRP. As we saw in $\S 1$, within NERP the general theory of intentionality can be seen as involving two chapters: the theory of source intentionality and the theory of non-source intentionality. The same general structure can be replicated within PIRP. Since within PIRP phenomenal intentionality is the source intentionality, within PIRP a general theory of intentionality would comprise two chapters, the theory of phenomenal intentionality and the theory of non-phenomenal intentionality.

\subsection{The Theory of Phenomenal Intentionality}

Recall that according to PIRP, intentionality is injected into the world with the appearance of the right kind of phenomenal character. The fundamental task of the theory of phenomenal intentionality is to identify the kind of phenomenal character whose appearance injects intentionality into the world. One way to think of the challenge is as seeking the phenomenological signature of directedness (Kriegel 2011 Ch.3). In the nature of things, it would have to be a very subtle phenomenal feature, one that may well be introspectively unimposing but quite pervasive in our stream of consciousness. ${ }^{28}$

One suggestion might be culled from Strawson (2008). As noted in $§ 2.3$, like others Strawson maintains that, distinctively, phenomenal intentionality has determinate content in and of itself. But unlike others, he makes a proposal about what it is that endows phenomenal intentionality with this content determinacy: it is the phenomenology of taking. The notion of "taking" is present already in Chisholm (1957), for whom the act through which the mind takes something to be thus-and-so is the fundamental intentional act, with other intentional states being elaborations or modifications of a core act of taking. For Strawson, taking is a component or aspect of cognitive phenomenology. There is a subtle phenomenological feature, cognitive rather than sensory in nature, whereby a conscious experience takes something to be thus-and-so. ${ }^{29}$ This phenomenal taking, as we might call it, determines the exact intentional content of a phenomenally intentional state. Every phenomenally intentional state has a phenomenal character that involves phenomenal taking as a component, and it is in virtue of this phenomenal taking that the state is intentional.

A different suggestion is due to Masrour (2008), who claims that it is only when a conscious experience exhibits a structural phenomenal feature he calls "objectual unity structure" (OUS) that it becomes intentional. Two phenomenal items are objectually unified in a perceptual experience, according to Masrour, just in case the experience presents them as belonging to the same 
object. Consider R. C. James's famous Gestalt-switch-provoking picture of the Dalmatian (reproduced, e.g., in Marr 1982). Once the switch occurs and the Dalmatian is "seen," certain black spots in one's visual experience become objectually unified while other spots are not so unified. The sensory aspect of the experience is the same before and after the switch, but after the switch the experience also exhibits a richer objectual-unity structure than before; it is only then that its phenomenal character intentionally represents a dog. ${ }^{30}$

I have considered two possible subtle phenomenal features that may serve as the "intentional spark" - the kind of phenomenal feature whose appearance injects intentionality into the world. Interestingly, it is often thought that all phenomenal character is intentional. If that is the case, and phenomenal taking or OUS is indeed the intentional spark, then it follows that phenomenal taking or OUS is a component in every phenomenal character, that is, that all phenomenal character involves taking or OUS.

But the view that all phenomenal character is intentional may also suggest a third and competing account of the subtle phenomenal feature that brings intentionality into the world. This is the suggestion that the relevant feature is phenomenality itself. By "phenomenality itself" I simply mean the most general phenomenal genus, that of which all others are species (or perhaps the phenomenal determinable of which every other phenomenal property is a determinate). On this view, the intentional spark is generic phenomenality.

Philosophers attracted to the idea that all phenomenality is intentional are often motivated by the claim that phenomenal character is diaphanous or transparent: when one introspects one's current conscious experience, one is only aware of what the experience represents (Harman 1990). So a fourth suggestion could be that transparency is the intentionality-injecting phenomenal feature. ${ }^{31}$ This suggestion would be coextensive with the last one if indeed all phenomenality is intentional. But it may be that not all phenomenality is intentional. Thus, it is sometimes held that while the transparency of experience is plausible for perceptual phenomenology (and certainly cognitive phenomenology), it is quite less plausible for somatic and emotional phenomenology. ${ }^{32}$ If this is the case, then the transparency suggestion and the generic-phenomenality suggestion would not coextend after all.

Of course, another option always available is to hold that the phenomenological signature of directedness is a sui generis phenomenal feature, inexplicable in terms of any other, simpler phenomenology. The view would be that the feature is exhibited by some mental states, such that when (and only when) it is exhibited, the relevant states are endowed with source intentionality. ${ }^{33} \mathrm{We}$ may call this feature sui generis phenomenal directedness. ${ }^{34}$

I have considered five options for identifying the phenomenal features that inject intentionality into the world: phenomenal taking, unity structure, generic phenomenality, transparency, and suigeneris phenomenal directedness. 
There are certainly other options worth exploring. ${ }^{35}$ The theory of phenomenal intentionality would attend to all those options-and to the reasons for preferring one over others.

Also within the province of the theory of phenomenal intentionality would be work on the scope and distinctiveness of phenomenal intentionality, reviewed in $\S 2.3$ and $\$ 2.4$. In addition, the theory of phenomenal intentionality would ultimately consider contingent properties of phenomenal intentionality that are not necessarily distinctive or special but do matter to its intentional function. For example, I suspect that in phenomenal intentionality the referential connection to the world works roughly as suggested in the descriptive theory of linguistic reference, rather than as suggested by direct-reference theories. If this is right, this would be of central importance to the theory of phenomenal intentionality, even if it does not constitute a distinctive feature of phenomenal intentionality.

\subsection{The Theory of Non-Phenomenal Intentionality}

A comprehensive theory of intentionality would require not only an account of the phenomenal character that serves as the source of intentionality but also an account of how that phenomenal character outsources intentionality. That is, a full understanding of source intentionality does not constitute an understanding of intentionality as such. The other chapter of the (PIRP-ly) theory of intentionality concerns the nature of non-phenomenal intentionality and how it is grounded in phenomenal intentionality. Surprisingly, perhaps, several options for such an account can already be found in the existing literature (see Kriegel 2011 Ch.4 for review and discussion). ${ }^{36}$

One account, due to Searle (1992), may be called potentialism. Recall that according to Searle, non-phenomenally intentional states are intentional in virtue of being potentially phenomenal. Thus, an unconscious belief that $p$ has $p$ as its content in virtue of the fact that if it were conscious it would have the phenomenal-intentional content that $p$. At the same time, linguistic expressions, pictures, and so on, are surely not even potentially conscious. So their intentionality must be grounded in mental intentionality in some other way, perhaps through the Gricean mechanism of intention-based semantics (see Grice 1957). We may thus propose that Searle's overall account of how non-phenomenal intentionality is grounded in phenomenal intentionality proceeds in two phases: the first extends intentionality from the narrow base of phenomenally intentional states to the realm of non-phenomenal mentality via counterfactuals about merely potential phenomenal character; the second extends it from the mental realm to the realm of non-mental intentionality via the right kind of speaker intentions. ${ }^{37}$

A second account may be called inferentialism (Loar 2003, Horgan and Graham forthcoming). On this view, non-phenomenally intentional states 
inherit their intentionality through inferential connections they bear to phenomenally intentional states within the overall cognitive architecture of the mind. Thus, an unconscious belief that $p$ is assigned just this content because it interacts with a conscious belief that $p \rightarrow q$ to bring about a conscious belief that $q$. Again, because non-mental items are not inferentially connected to mental ones, this would require supplementation in the form of an account of how non-mental intentionality is grounded in mental intentionality.

A third account may be called interpretivism (Kriegel 2011 Ch.4). This view proposes a unified account of non-mental and mental non-phenomenal intentionality according to which all such intentionality is bestowed by phenomenally conscious interpretation. For example, an unconscious belief that $p$ has $p$ as its content in virtue of the fact that the best (conscious) interpretation of the system whose state it is would assign to the system a belief that $p$; and ditto for any linguistic expression or picture with the content that $p$.

Of course, there is also a fourth option, which is to deny the existence of non-phenomenal intentionality altogether; we may call it eliminativism (Georgalis 2006, Strawson 2008). ${ }^{38}$ On this view, there is no problem of grounding non-phenomenal intentionality in phenomenal intentionality, because the former does not exist. Thus a full account of phenomenal intentionality, perhaps along the lines of one of the options mentioned in $\S 3.1$, would constitute a comprehensive theory of intentionality.

As before, I am not concerned here with how plausible these accounts are; their portraits given here are too summary to allow serious discussion of their merits anyway. My discussion here serves only to point out some available options for accounting for non-phenomenal intentionality. In different combinations with the accounts of phenomenal intentionality covered in $\S 3.1$, they would constitute different comprehensive theories of intentionality. For example, one comprehensive theory might combine the phenomenal-taking view of phenomenal intentionality with potentialism about non-phenomenal intentionality; another the sui generis phenomenal directedness view with inferentialism about non-phenomenal intentionality; yet another the transparency view of phenomenal intentionality with interpretivism about non-phenomenal intentionality; and so on. Some combinations may be somehow more natural than others, but all would appear coherent and thus antecedently viable as comprehensive theories of intentionality in the PIRP genre.

\section{Conclusion}

Work on intentionality within analytic philosophy of mind has been dominated for the past four decades by the idea that intentionality comes into the world when a certain type of tracking relation appears. In the last decade or so, 
however, another approach has been gaining momentum, suggesting that it is rather the appearance of a certain type of phenomenal character that injects intentionality into the world. From and around this newer approach a cluster of observations, contentions, and debates has emerged that has enlivened philosophical discussions of the mind, prompting philosophers to take a fresh look at the phenomenon of intentionality. The claim I have been making in this chapter is that the work pertaining to the cluster is ready to be consolidated into a well-defined, clearly organized, self-conscious research program. ${ }^{39}$

\section{Notes}

1. First accounts in this vein, such as Dennis Stampe's (1977) and Fred Dretske's (1981), were focused on broadly causal or informational relations. Under the influence of Ruth Millikan $(1984,1989,1993)$ and David Papineau $(1984,1993)$, many philosophers have incorporated a teleological aspect into their account of the relevant relation (see Dretske 1988, McGinn 1989, Neander 1995).

2. I cannot make the case for this claim here, but my suspicion that it is only phenomenal intentionality which is concerned in those debates arises from the fact that unconscious mental states were not widely recognized before Freud's work on repression and the postulation in cognitive science of myriad sub-personal unconscious states. Brentano (1874) himself argued explicitly for the co-extension of the mental, the conscious, and the intentional. So it is only natural to interpret him, and hence his students, as concerned with phenomenal intentionality. There is interesting historical research to be done here.

3. I am assuming here that linguistic intentionality is derived. Some proponents of NERP disagree (e.g., Millikan 1984), arguing [that the tracking property in virtue of which mental states represent non-derivatively is exhibited by linguistic expressions as well.]

4. There is a limit-case version of NERP, too. According to Dennett (1990), all intentionality is derived (none is underived), so in general the intentionality of derivatively intentional states must derive from each other's, without being ultimately grounded in underived intentionality.

5. In principle, the second chapter could be exactly the same in a NERP-ly theory and a PIRP-ly theory. In particular, there is no reason to suppose that the derivation relation cannot be thought of in the same way by both. However, the nature of the sources of derivation is likely to constrain theorizing about the nature of the derivation, so the radical difference between the sources might very well lead to very different accounts of derived intentionality.

6. I am indebted to Terry Horgan for this distinction.

7. One limit-case epistemic possibility is that there is not really any spread at all, because the only intentionality there is is the intentionality of phenomenal consciousness itself (more on this in 2.4).

8. I will offer some remarks in the present section about different ways of potentially cashing out the theses as vaguely and generically stated, but more will be said on such matters in $\S 2$.

9. I am indebted to Terry Horgan for this formulation.

10. Some of these matters will be further pursued later in the chapter.

11. This issue can get complicated by matters terminological. Some, like Georgalis (2006), reserve "phenomenal" for the sensory kind of what-it's-like-ness (more or less stipulatively), while yet recognizing the what-it's-like-ness of thought. This looks to be probably just a verbal disagreement with those who claim there is a phenomenology of thought. 
12. This is the metaphysical picture of phenomenal consciousness embraced by Chalmers (1996), as I understand him. Chalmers holds that phenomenal properties supervene on physicalistically naturalizable ones with nomological necessity, and that the pertinent supervenience laws are ontologically brute. He also regards his metaphysical picture as a form of naturalism about phenomenal consciousness, but not as a physicalistic version of naturalism. For clearer examples of naturalistic PIRP, see McGinn 1988 and Kriegel 2011 Ch.2.

13. Horgan and Tienson's (2002) descriptions of certain conscious episodes can be seen as attempting to tap into an idea of this sort.

14. The present use of "sensory" and "non-sensory" pertains, in effect by stipulation, to relatively raw aspects of one's sense-induced experience. It is a non-trivial matter to get a more formal specification of these terms going.

15. What that feature is is elucidated in terms of paradigmatic examples, which Masrour describes in detail but which I will not reproduce here.

16. Weaker theses might suggest that there is an individuative but non-proprietary cognitive phenomenology (say, because every belief is accompanied by imagery, and the imagery varies with the belief's content); or that there is a proprietary but non-individuative phenomenology (say, because although beliefs in general are phenomenally different from hopes, suppositions, and other propositional attitudes, it is not the case that a belief that $p$ is phenomenally different from a belief that $q$ for any $p$ and $q$ ).

17. For other arguments of this form, see Peacocke 1998, Horgan and Tienson 2002, Kriegel 2003a, and Pitt 2004.

18. Different authors have focused on different types of threat to content determinacy. Searle (1992) focuses on the threat to the intensionality of content; Loar (1995), Georgalis (2006), and Horgan and Graham (forthcoming) on the Quinean threat of referential inscrutability; Strawson (2008) on the threat once referred to as the "horizontal disjunction problem," the thought that tracking theories of content cannot discriminate between different links in a causal chain leading up to an intentional state.

19. Here as elsewhere, there are difficult questions surrounding the explication of intrinsicality. The relevant notion for our present purposes is that of a state instantiating a certain property not in virtue of standing in a relation to some other state, but in and of itself.

20. For a fuller discussion of these issues, see Kriegel forthcoming.

21. An exception is McGinn (1988), who argues that conscious intentionality is wide, and its being both wide and in some way present to the subject is part of what makes it so mysterious.

22. As mentioned in a previous note, Georgalis would not state the thesis this way but would probably subscribe to it as interpreted by us. Perhaps it is also worth noting that Strawson does not use the term "phenomenal intentionality" but instead the term "experiential intentionality." This is potentially better in avoiding confusion with the more sensory reading of the term "phenomenal."

23. An even weaker thesis would require non-experiential intentional states to bear the requisite relations not necessarily to phenomenal-intentional states but also possibly to merely potentially phenomenal-intentional states. I am not familiar with any defense, nor defender, of this latter claim.

24. The argument thus proceeds as follows: 1) Only phenomenal intentionality has inherently scrutable content; 2) Only intentionality with inherently scrutable content is basic; therefore, 3) Only phenomenal intentionality is basic. Essentially the same argument for the special status of phenomenal intentionality is presented by Horgan and Graham (forthcoming), who develop the argument quite a bit further.

25. This kind of fined-grained content is what Searle (1992) refers to as "aspectual shape." His argument could thus be construed as follows: 1) Only phenomenal intentionality is non-derivatively aspectually shaped; 2) Only non-derivatively aspectually shaped intentionality is basic; therefore, 3) Only phenomenal intentionality is basic.

26. Similarly, Georgalis (2006) insists that only conscious intentionality involves essentially not only the two-place relation $x$ represents $y$ but also the three-place relation $x$ represents 
$y$ to $z$. However, Georgalis argues that there is an important difference between phenomenal and conscious intentionality and does not make the same claim about phenomenal intentionality.

27. One objection, due to Shani (2008), is that although proponents of phenomenal intentionality (most notably Loar and Georgalis) are right that a full theory of intentionality must incorporate a certain first-person notion, there are ways to do so without appealing to phenomenal intentionality. In particular, Shani argues that the central aspect of first-person intentionality would be a notion of idiosyncratic perspective, but such a perspective can be accounted for in naturalistic, indeed broadly teleological, terms that appeal solely to unconscious and non-phenomenal phenomena.

28. These two may not be unrelated: the most pervasive features of phenomenology are often hardest to spot, because hardest to isolate (there may be no vivid contrasts between presence and absence).

29. Note that if taking is a cognitive phenomenal feature, and is necessary for phenomenal intentionality, then all phenomenal intentionality is cognitive, at least in the sense that phenomenal character must have at least one cognitive element in order to be intentional. This may raise the objection that certain animals and neonates may be robbed of intentionality. There are probably reasonable responses to this objection, but a full discussion would take us too far afield. (Moreover, some of the moves here would parallel relatively familiar moves from discussions in the theory of animal consciousness and the problem it presents for higher-order thought theories.)

30. The pre-switch visual experience is already intentional: it represents an externally situated pattern of black and white splotches. Still, it may be that there must be some unity structure present in order for the visual phenomenology to become intentional. It may be, too, that virtually all visual phenomenology already has some unity structure and is already intentional.

31. This requires that we think of transparency as a positive phenomenal feature, exhibited by some (or all) experiences, rather than as the absence of certain phenomenal features, as it sometimes is.

32. This is not to say that the transparency thesis has not been defended for such experiences as well (Shoemaker 1994, Tye 2000). But it is roundly accepted that such defenses tend to be more theoretical and rely less on the immediate intuitive conviction that the thesis enjoys in the perceptual domain.

33. It would be a substantive question at this point whether all phenomenal states have this phenomenal feature. (It is, of course, coherent to hold either that only some do or that all do.) Which way one goes on this question will then have implications for any possible coextension between the present suggestion and the generic-phenomenality suggestion.

34. Methodologically, it is probably preferable to seek a more explanatory account of the kind of phenomenal character we are seeking and settle for an account of it in terms of sui generis phenomenal directedness only as a last resort.

35. See Kriegel 2011 Ch.3 for discussion of two more suggestions, one of which is developed from Frey's (this volume) discussion.

36. Gricean intention-based semantics, although the leading approach within NERP, cannot be straightforwardly applied within PIRP because the relevant intentions Grice identifies are presumably unconscious. It is very possible, however, to divide the theory of derived intentionality within PIRP into two parts, the first concerned with the derivation of non-mental intentionality from non-phenomenal mental intentionality via the Gricean mechanism and the second concerned with the derivation of non-phenomenal mental intentionality from phenomenal intentionality via some other mechanism. (For more discussion, see Kriegel 2011.)

37. Note that these intentions, at least those proposed by Grice, are typically unconscious. So the derivation of linguistic intentionality from conscious intentionality would have to proceed in two steps: it would not be possible for the former to derive directly from the latter. 
38. It is also possible to interpret Georgalis (2006) and Pitt (Ms) as holding this position. Georgalis maintains that there is no unconscious intentionality, and although he allows that some conscious intentionality is non-phenomenal, this is mainly because, as remarked earlier, his notion of phenomenality is narrower and applies only to sensory quality. Pitt, by contrast, allows that there is unconscious intentionality but proposes that such intentionality is constituted by an unconscious phenomenality. Thus although there is such a thing as unconscious intentionality, there is no non-phenomenal intentionality.

39. For comments on a previous draft, I would like to thank Ben Blumson, Curtis Brown, Tamar Szabó Gendler, Kristin Hurlburt, Adam Pautz, Galen Strawson, and especially Brie Gertler and Susanna Siegel.

\section{References}

Abell, C. 2005. “Pictorial Implicature." Journal of Aesthetics and Art Criticism 63: 55-66.

Blumson, B. 2006. Resemblance and Representation. PhD Dissertation, Australian National University.

Bourget, D. 2010. “Consciousness Is Underived Intentionality.” Noûs 44: 32-58.

Brentano, F. 1874. Psychology from Empirical Standpoint. Edited by O. Kraus. English edition L. L. McAlister, ed. Translated by A. C. Rancurello, D. B. Terrell, and L. L. McAlister. London: Routledge and Kegan Paul, 1973.

Chalmers, D. J. 1996. The Conscious Mind. Oxford: Oxford University Press.

Chisholm, R. 1957. Perceiving: A Philosophical Study. Ithaca: Cornell University Press.

Cummins, R. 1979. "Intention, Meaning, and Truth Conditions." Philosophical Studies 35: 345-360.

Davies, M. 1995. "Consciousness and the Varieties of Aboutness." In C. Macdonald and G. Macdonald (eds.), Connectionism: Debates on Psychological Explanation (Vol. II). Oxford: Blackwell.

Dennett, D.C. 1990. “The Myth of Original Intentionality.” In K. A. Mohyeldin Said, W. H. Newton-Smith, R. Viale, and K. V. Wilkes (eds.), Modeling the Mind. Oxford: Oxford University Press.

Dretske, F. I. 1981. Knowledge and the Flow of Information. Oxford: Clarendon.

Dretske, F. I. 1988. Explaining Behavior. Cambridge, MA: MIT Press.

Fodor, J. A. 1984. “Semantics, Wisconsin Style." Synthese 59: 231-250.

Fodor, J. A. 1990. A Theory of Content and Other Essays. Cambridge MA: MIT Press.

Georgalis, N. 2006. The Primacy of the Subjective. Cambridge MA: MIT Press.

Goldman, A. 1993. "The Psychology of Folk Psychology." Behavioral and Brain Sciences 16: 15-28.

Grice, H. P. 1957. “Meaning.” Philosophical Review 66: 377-388.

Grice, H. P. 1969. “Utterer's Meaning and Intention.” Philosophical Review 68: 147-177.

Harman, G. 1990. “The Intrinsic Quality of Experience.” Philosophical Perspectives 4: 31-52.

Horgan, T. and G. Graham Forthcoming. "Phenomenal Intentionality and Content Determinacy." In R. Schantz, Prospects for Meaning. Amsterdam: de Gruyter.

Horgan, T. and U. Kriegel 2008. "Phenomenal Intentionality Meets the Extended Mind." Monist 91: 353-380

Horgan, T. and J. Tienson 2002. “The Intentionality of Phenomenology and the Phenomenology of Intentionality.” In D. J. Chalmers (ed.), Philosophy of Mind: Classical and Contemporary Readings. Oxford: Oxford University Press.

Horgan, T., J. Tienson, and G. Graham 2004. "Phenomenal Intentionality and the Brain in a Vat." In R. Schantz (ed.), The Externalist Challenge: New Studies on Cognition and Intentionality. Amsterdam: de Gruyter.

Horgan, T., J. Tienson, and G. Graham 2006. "Internal-World Skepticism and Mental Self-Presentation." In U. Kriegel and K. W. Williford (eds.), Self-Representational Approaches to Consciousness. Cambridge MA: MIT Press. 
Husserl, E. 1901. Logical Investigations, Vol. 2. Trans. J.N. Findlay. London: Routledge, 2001.

Jackson, F. 1998. From Metaphysics to Ethics: A Defence of Conceptual Analysis. Cambridge: Cambridge University Press.

Kelly, S. D. 2004. “On Seeing Things in Merleau-Ponty.” In T. Carmon (ed.), Cambridge Companion to Merleau-Ponty. Cambridge: Cambridge University Press.

Kriegel, U. 2003a. "Consciousness as Sensory Quality and as Implicit Self-Awareness." Phenomenology and the Cognitive Sciences 2: 1-26.

Kriegel, U. 2003b. "Is Intentionality Dependent upon Consciousness?" Philosophical Studies 116: 271-307.

Kriegel, U. 2005. “Naturalizing Subjective Character." Philosophy and Phenomenological Research 71: $23-57$.

Kriegel, U. 2007. "Intentional Inexistence and Phenomenal Intentionality." Philosophical Perspectives 21: 307-340.

Kriegel, U. 2009. Subjective Consciousness: A Self-Representational Theory. Oxford: Oxford University Press.

Kriegel, U. 2011. The Sources of Intentionality. Oxford: Oxford University Press.

Kriegel, U. Forthcoming. "Brentano's Most Striking Thesis: No Representation without Self-Representation.” In D. Fisette and G. Fréchette (eds.), Themes from Brentano.

Kriegel, U. Ms. "Intentionality: Realization versus Essence."

Levine, J. 2001. Purple Haze. Oxford: Oxford University Press.

Loar, B. 1987. "Subjective Intentionality.” Philosophical Topics 15: 89-124.

Loar, B. 1995. "Reference from the First-Person Perspective." Philosophical Issues 6: 53-72.

Loar, B. 2003. "Phenomenal Intentionality as the Basis for Mental Content." In M. Hahn and B. Ramberg (eds.), Reflections and Replies: Essays on the Philosophy of Tyler Burge. Cambridge MA: MIT Press.

Lycan, W. G. 2008. "Phenomenal Intentionalities.” American Philosophical Quarterly 45: 233-252.

McGinn, C. 1988. “Consciousness and Content.” Proceedings of the British Academy 76: 219-239. Reprinted in N. J. Block, O. Flanagan, and G. Güzeldere (eds.), The Nature of Consciousness: Philosophical Debates. Cambridge, MA: MIT Press, 1997.

McGinn, V. 1989. Mental Content. Oxford: Blackwell.

Marr, D. 1982. Vision. San Francisco: W. H. Freeman.

Masrour, F. 2008. Structuralism: In Defense of a Kantian Account of Perceptual Experience. PhD Dissertation, University of Arizona.

Meinong, A. 1904. "The Theory of Objects," in Roderick M. Chisholm (ed.), Realism and the Background of Phenomenology, Glencoe, IL: Free Press, 1960.

Millikan, R. G. 1984. Language, Thought, and Other Biological Categories. Cambridge, MA: MIT Press.

Millikan, R. G. 1989. “Biosemantics.” Journal of Philosophy 86: 281-297.

Millikan, R. G. 1993. White Queen Psychology and Other Essays for Alice. Cambridge, MA: MIT Press.

Moore, G. E. 1953. "Propositions.” In his Some Main Problems of Philosophy. Oxford: Routledge.

Neander, K. 1995. “Misrepresenting and Malfunctioning.” Philosophical Studies 79: 109-141.

Noë, A. 2004. Action in Perception. Cambridge MA: MIT Press.

Papineau, D. 1993. Philosophical Naturalism. Oxford: Blackwell.

Peacocke, C. 1998. "Conscious Attitudes, Attention, and Self-Knowledge." In C. Wright, B. C. Smith, and C. Macdonald (eds.), Knowing Our Own Minds. Oxford: Oxford University Press.

Pitt, D. 2004. “The Phenomenology of Cognition; or What Is It Like to Think that P?," Philosophy and Phenomenological Research 69: 1-36.

Pitt,D.Ms. “UnconsciousIntentionality."http://www.calstatela.edu/faculty/dpitt/Unconscious \%20Intentionality.pdf

Schiffer, S. 1982. "Intention Based Semantics." Notre Dame Journal of Formal Logic 23: 119-159.

Searle, J. R. 1983. Intentionality: An Essay in the Philosophy of Mind. Oxford: Blackwell.

Searle, J. R. 1991. “Consciousness, Unconsciousness, and Intentionality." Philosophical Issues 1: $45-66$. 
Searle, J. R. 1992. The Rediscovery of Mind. Cambridge MA: MIT Press.

Shani, I. 2008. "Against Consciousness Chauvinism." The Monist 91(2): 294-323.

Shoemaker, S. 1994. "Phenomenal Character." Nous 28: 21-38

Siegel, S. 2005. "The Contents of Perception." Stanford Encyclopedia of Philosophy.

Siegel, S. 2006a. "Which Properties Are Represented in Perception?" In T. Gendler Szabo and

J. Hawthorne (eds.), Perceptual Experience. Oxford: Oxford University Press.

Siegel, S. 2006b. "Subject and Object in the Contents of Visual Experience." Philosophical Review 115: 355-388.

Siewert, C. P. 1998. The Significance of Consciousness. Princeton NJ: Princeton University Press.

Stampe D. 1977. "Towards a Causal Theory of Linguistic Representation." Midwest Studies in Philosophy 2: 42-63.

Strawson, G. 1994. Mental Reality. Cambridge, MA: MIT Press.

Strawson, G. 2008. “Real Intentionality 3: Why Intentionality Entails Consciousness.” In his Real Materialism and Other Essays. Oxford: Oxford University Press.

Twardowski, K. 1894. On the Content and Object of Presentations. Trans. R. Grossmann. The Hague: Martinus Nijhoff, 1977.

Tye, M. 2000. Consciousness, Color, and Content. Cambridge, MA: MIT Press. 